\title{
The travels of a lone star tick
}

\author{
J M Alderdice, I F Burgess
}

\begin{abstract}
A lone-star tick, Amblyomma americanum, was found as a pedunculated lesion on the back of the arm of an 84 year old man in Northern Ireland. This was acquired on a visit to the USA. The tick is found mainly in Texas and the Ozark mountains of Missouri, with scattered foci in other parts of southern USA. It is the vector of Rocky Mountain spotted fever. As worldwide travel becomes increasingly common, exotic parasites make occasional appearances in northern Europe. $(\mathcal{F}$ Clin Pathol 1998;51:403)
\end{abstract}

Keywords: lone-star tick; Amblyomma americanum

An 84 year old man presented to his general practitioner in Northern Ireland with a strange pedunculated lesion on the back of the arm which appeared a little infected. It was removed by cautery and submitted to the histopathology laboratory.

The oval polypoid lesion measured $1 \mathrm{~cm}$ in length and had a finely mottled surface. Close examination under a stereo microscope showed a round body with eight legs, and mouth parts visible. As the finer classification of this tick was outside the experience of a general histopathologist, it was referred to a medical entomologist who identified it as an almost fully engorged adult female of the lone-star tick, Amblyomma americanum (fig 1). This species is found mainly in Texas and the Ozark mountains of Missouri, with scattered foci in other parts of southern USA. When curetted off, it would have been in situ for at least one week. The state of engorgement would have reached the stage of releasing excess fluid from the meal, with the possibility of disease transmission. However, the symptoms of the principal infective condition, Rocky Mountain spotted fever, would probably already have been evident by the time of presentation.

Acquisition of the tick would have been from low growing but relatively dense foliage either early in the morning or during the evening when the atmospheric humidity rises. As lonestar ticks should not be indigenous to Northern

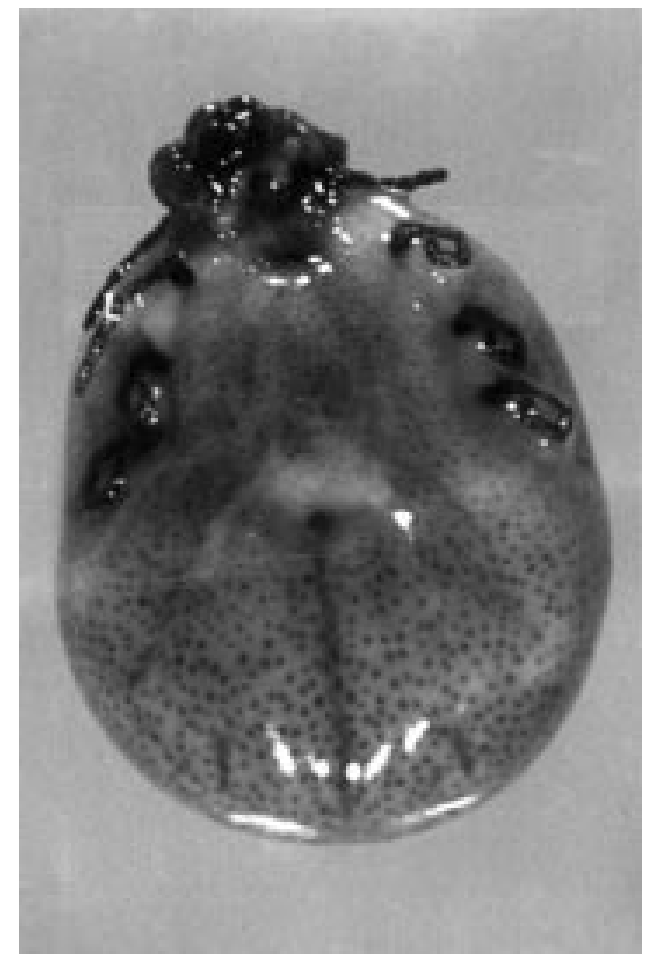

Figure 1 Adult female lone-star tick.

Ireland we made tentative inquiries as to whether the 84 year old patient might have travelled to southern USA. The story was completed when we discovered that he had visited his son who lives in St Louis, Missouri, for a two month vacation this summer and consulted his general practitioner a couple of days after returning, when the engorged tick made its presence felt. His serology is negative. Had this animal not been discovered when it was, it would have dropped off the patient within another day or two. Female ticks are mated before they feed, so it would then have laid around 6000 to 7000 eggs which could have started an unusual focus of this exotic parasite on the Antrim coast of Northern Ireland.

We acknowledge the assistance of Dr Haggan, general practitioner, in providing the specimen and consulting with the patient. 